\title{
Induction of Immune Responses and Immune Evasion by Human Bocavirus
}

\author{
Rauf Bhat Fahad N. Almajhdi \\ Virology Research Group, Department of Botany and Microbiology, College of Science, King Saud University, \\ Riyadh, Saudi Arabia
}

\section{Keywords}

Bocavirus virus · Immune evasion · Vaccines · Escape mechanism $\cdot$ Antibodies

\begin{abstract}
Respiratory tract infections are the primary cause of morbidity and mortality globally. Human bocavirus 1 (HBoV1), a member of the Parvoviridae family causes a wide spectrum of respiratory diseases in children, and gastroenteritis in adults. The mechanisms of latency, persistence, and reinfection of Bocavirus are poorly understood at present due to the lack of permissive cell lines and efficient animal models. Moreover, the dual infections of $\mathrm{HBoV}$ and other respiratory viruses further complicate the study of the pathogenicity of Bocaviruses. The data on immunological consequences of Bocavirus infection are sparse. However, the existing data have highlighted the role of CD4 T cells in Bocavirus infection. High titres of HBoV-specific antibodies have been detected in different populations suggesting its ubiquitous prevalence. Interestingly, the mechanism employed by Bocavirus to evade the immune system mostly targets type I IFN pathways and cause pyroptotic cell death of host cells. This review summarizes the immune responses evoked in response to Bocavirus infection, escape mechanism employed by the virus, and the vaccination strategies, including antisense technology to combat Bocavirus infections.
\end{abstract}

\section{Introduction}

\section{Biology of Bocaviruses}

Human bocavirus (HBoV) was first isolated in Sweden in 2005 in young children harbouring infections of the lower respiratory tract [1]. Later, 3 additional bocaviruses, HBoV 2, 3, and 4, with high sequence homology were discovered in 2009-2010 in human faeces [2]. HBoV, member of the family Parvoviridae, subfamily Parvovirinae, and genus Bocavirus, is small, autonomous, icosahedral, nonenveloped viruses (18-26 $\mathrm{nm}$ in diameter) containing a single molecule of linear, and single-stranded DNA (around $5 \mathrm{kbs}$ ). Genomic analyses of $\mathrm{HBoV}$ strains have been challenging owing to limitations of in vitro culture. Genomically, HBoV1 is more diverse than HBoV2-4, and the genetic diversity within HBoV2-4 is even greater. The genome of $\mathrm{HBoV}$ consists of following 3 open reading frames (ORFs): ORF1 encodes 2 forms of the nonstructural (NS) protein NS1; ORF2 encodes the nuclear phosphoprotein NP1, unique for bocavirus; and ORF3 encodes the 2 structural viral capsid proteins, VP1 and VP2. The noncoding regions contain palindromic sequences essential for viral replication. NS1 plays critical a role in DNA replication while NS2, NS3, and NS4 proteins contain the predictive domains of NS1 activities important for viral

Edited by: H.-U. Simon, Bern.
Correspondence to:

Rauf Bhat, rauf012@yahoo.com 


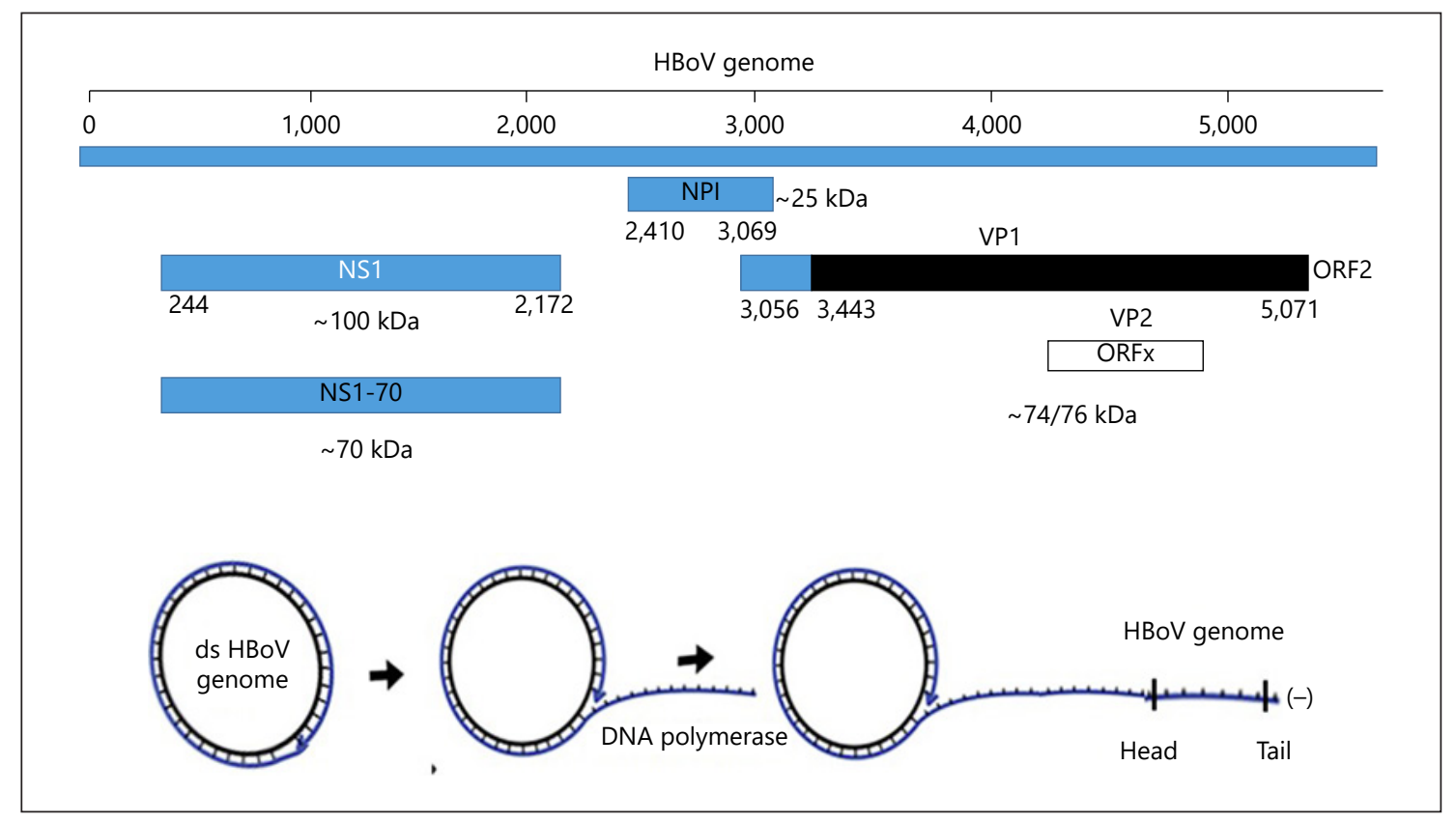

Fig. 1. Upper figure: Genomic organization of HBoV1. The genes encoding the protein NS1, NP1 and VP1/VP2 (capsid proteins), and with major ORFs are shown. Lower figure: Proposed classical rolling-circle model of $\mathrm{HBoV}$ DNA replication. Progeny DNA of negative polarity is replicated from the positive-strand genome that circularizes head-to-tail PCR products. VP, viral (structural) protein; NS, nonstructural protein; NP, nuclear phosphoprotein, $\mathrm{HBoV}$, human bocavirus; ORF, open reading frame.

DNA replication. NP1, a small NS protein, is involved in the expression of viral capsid proteins and DNA replication. VP1 and VP2 share a common C-terminal region and differ in the N-terminal region of VP1 having phospholipase A2 activity and crucial for infectivity $[3,4]$.

Due to the absence of laboratory culture or an animal model, the replication mechanism of $\mathrm{HBoV} 1$ remains elusive. Based on phylogenetic analyses, it has been hypothesized that $\mathrm{HBoV}$ follows the rolling hairpin model for its replication. In this replication model, the replication intermediates are concatemers having either headto-head or tail-to-tail structure forming progeny genomes packaged into new viral particles. Moreover, $\mathrm{HBoV}$ during natural infection establishes in host cells by forming extrachromosomal closed circular episomes [57]. The genome organization and replication model of $\mathrm{HBoV}$ has been shown in Figure 1a and $b$.

\section{Pathogenicity}

$\mathrm{HBoV}$ causes lower respiratory tract infection, acute wheezing, pneumonia, and bronchial asthma in children, and gastrointestinal infections in adults. $\mathrm{HBoV}$ infection cases show a high rate of coinfection (up to 83 per cent) with many viral and bacterial respiratory, and gastroenteritis pathogens. The transmission and infection of $\mathrm{HBoV}$ take place throughout the year worldwide, predominantly during winter and spring months $[5,8]$.

The data on pathogenicity and immunogenicity of $\mathrm{HBoV}$ are limited due to lack of an efficient in vitro $\mathrm{HBoV}$ culture system and the absence of an animal model [9, 10]. Existing knowledge is mostly an extrapolation of parvovirus B19V capsid studies which describe viral capsid proteins as immunodominant targets of host immune response. These reports suggest a possibly similar role for $\mathrm{HBoV}$ capsid proteins in virus-induced immunity [11]. Available reports so far indicate the active role of Th1 cells in response to $\mathrm{HBoV} \mathrm{VP}$ proteins. The strategies employed by Bocaviruses to evade host immune response mostly operate through manipulation of hosts IFN type I pathway to prolong the persistence and replication of the virus. Vaccination studies against $\mathrm{HBoV}$ mostly focus on the immunogenicity of VP2 VPL proteins, similar to VP2 of Parvovirus, B19 [12-14]. Keeping in view the clinical manifestations of $\mathrm{HBoV}$, there is an urgent need to elucidate the pathogenicity and immunogenicity of $\mathrm{HBoV}$ infection to develop strategies to combat $\mathrm{HBoV}$ infection. 


\section{T- and B-Cell Responses against Bocaviruses}

The adaptive immune response, which includes both T- and B-cell-based cellular immunity, constitute an important arm of the immune system to counteract invading pathogens. T-helper cells are vital for antiviral immunity and activate cytotoxic T and NK cells whereas B cells produce antibodies that help to neutralize microbial invasions [13-15]. The role of $\mathrm{T}$ cells in immune responses against Bocaviruses is still unclear. The data available on $\mathrm{HBoV}$-specific T cell immunity are still meagre. Numerous studies of related parvovirus B19V have described viral capsid proteins as immunodominant targets of the cellular and humoral immune response suggesting a possibly similar role for $\mathrm{HBoV}$ capsid proteins in virus-specific immunity $[16,17]$.

High seroprevalence of up to $100 \%$ of HBoV VP1-specific IgG antibodies was detected in infants of the Japanese population. In $\mathrm{HBoV}$ seronegative cases, HBoV VP2-specific T-cell responses were absent, suggesting HBoV VP1 antigen specificity of the detected $\mathrm{T}$-cell responses. $\mathrm{HBoV}$ specific T-cell responses were highest in early childhood, thereafter declining with age due to less frequent exposure to the pathogen. Interestingly, female subjects showed higher numbers of IFN- $\gamma$ secreting cells than males, possibly due to more frequent contact with the infected children [17]. Another study demonstrated a significant boost in the secretion of VP2-specific IFN- $\gamma$ as compared to control stimulations in $\mathrm{HBoV}$-seropositive healthy adults, suggesting a high prevalence of $\mathrm{HBoV}$ among humans and presence of virus-specific T-cell responses [16].

Noteworthy, $\mathrm{HBoV}$-specific T-cell responses in terms of T-cell proliferation, IFN- $\gamma$, IL-10, and IL-13 levels in asymptomatic adults using recombinant HBoV VP2 (VLP) as antigen showed a positive correlation with B19-seropositive subjects. Importantly, T-cell responses were found to mostly mediated by CD4+ T cells rather than CD8+ T cells in response to stimulation with HBoV VP2-VLP. The $\mathrm{HBoV}$-specific Th-cell reactivity was observed to be quite high in some subjects possibly due to the booster effect of HBoV reinfections or other cross-reactive viruses [18].

Viral infections, including those caused by $\mathrm{HBoV}$, stimulate cellular immunity and cause an immunological imbalance between Th1 and Th2 patterns, resulting in recurrent episodes of wheezing in children $[19,20]$. An elevation of both Th1 and Th2 cytokines was observed in children with HBoV-related acute bronchiolitis compared to normal controls. $\mathrm{HBoV}$-induced Th1-responses (via IL-2, IFN- $\gamma$ ) lead to virus elimination and Th2 cytokines (via IL-10, IL-13) result in wheezing [21].
A differential prevalence of $\mathrm{HBoV1-4}$-specific antibodies was reported in children $(80,48,10$, and $0 \%$, respectively), with significantly weaker IgG responses among children with pre-existing HBoV2 IgG and vice versa. These observations are attributed to the phenomena called "original antigenic sin," where a primary infection by a virus curbs the immune response directed at the unique epitopes of a related virus [22]. It was also noted that primary $\mathrm{HBoV} 1$ infection was present in the majority of children at a mean age of 2.3 years but later surpassed by secondary infections and IgG antibody seroconversion. Moreover, $\mathrm{HBoV} 1$ primary infection was associated with respiratory illness and acute otitis media rather than secondary infection emphasizing the fact that $\mathrm{HBoV} 1$ is a true respiratory pathogen [23]. Long-term prevalence of HBoV-VP2-IgG antibodies was detected among $44 \%$ of immunocompetent adults followed serologically for an average of 16 years. However, to what extent the $4 \mathrm{HBoV} 1$, cross-react in the generation of heterologous anamnestic or secondary responses with $\mathrm{HBoV}$ remains unclear $[24,25]$. Interestingly, antibodies against $\mathrm{HBoV}$, WUPyV, and KIPyV polyomaviruses were widely prevalent in sera of healthy German adults suggesting that primary infections with these viruses are quite prevalent during childhood and youth [26].

$\mathrm{HBoV}$ dual infections with other respiratory viruses are observed frequently compared to mono HBoV infections. Multiple infections due to $\mathrm{HBoV}$ and other respiratory viruses such as human rhinovirus (RV), RSV, adenovirus, norovirus, rotavirus aggravate the immune response and result in acute wheezing in children $[6,8,25$, 27]. Comparison of the Th1/Th2-type cytokine profiles in young children with RV- and HBoV1-associated wheezing children showed higher pro-inflammatory, Th1 and Th2 type (IL-1 $\beta$, IL-7, IL-8, IL-2, IL-4, and IL13) responses as compared to $\mathrm{HBoV} 1$ alone. Dual infection with RV and HBoV1 resulted in a modified nonTh2-type cytokine response suggesting that HBoV1 may interfere with $\mathrm{RV}$-induced immune responses and inter. viral interaction in co-infections may further modulate them [28]. The immune responses evoked by $\mathrm{HBoV}$ have been graphically depicted in Figure 2.

\section{Human Bocavirus Infection and Asthma Development}

Respiratory tract infections due to viruses are the dominant cause of acute wheezing in children and infants leading to the development of asthma. RSV and RV as 


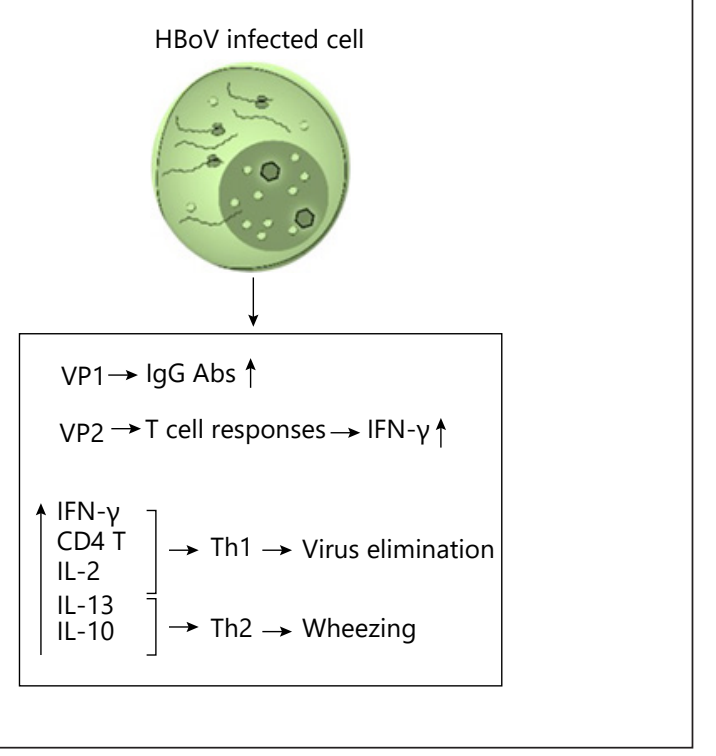

Fig. 2. Cellular and humoral immune response to $\mathrm{HBoV}$ infection. $\mathrm{HBoV}$ viral capsid proteins are immunodominant targets of the cellular and humoral immune response in virus-specific immunity. High seroprevalence of HBoV VP1-specific IgG antibodies in infants and $\mathrm{HBoV}$ VP2-specific T-cell responses, mostly CD4 mediated and enhanced IFN-g has been observed in adults. $\mathrm{HBoV}$ induced Th1-responses (via IL-2, IFN- $\gamma$ ) lead to virus elimination and Th2 cytokines (via IL-10, IL-13) result in wheezing. In case of dual infections with other viruses, the balance is more towards non-Th 2-type cytokine response. HBoV, human bocavirus.

causes of childhood wheezing and atopy have been extensively studied, and however, the role of $\mathrm{HBoV}$ in causing wheezing and atopy is still under investigation. It was found in polish children that viral involvement in wheezing was significant (83.2\%), with both $\mathrm{HBoV}$ and metapneumovirus, hMPV at around $11.9 \%$. These data point to the possible relationship of $\mathrm{HBoV}$ in causing wheezing combined with atopy in children [29]. In another interesting study, it was observed that infants with RSV-induced bronchiolitis had more severe disease and were younger than infants with $\mathrm{HBoV}$-induced bronchiolitis who had mild bronchiolitis. Moreover, HBoV increased the severity of bronchiolitis in infants co-infected with $\mathrm{RSV}$, supporting the pathogenic role of this virus in respiratory diseases in children. These data support the notion that although RSV is the major pathogen causing bronchiolitis, and however, viruses such as $\mathrm{HBoV}$ are also involved solely or as dual infections [30]. To lend support to these findings, it was demonstrated that severe $\mathrm{HBoV}$ caused bronchiolitis with recurrent wheezing and asthma and this accounted for approximately $10 \%$ of children

Immune Responses during Bocavirus Infection hospitalized [31]. In contrast, a Finnish study reported that there was no association between $\mathrm{HBoV}$-induced bronchiolitis/wheezing with atopic characteristics. It can be speculated that more detailed studies based on demography, genetic predisposition, etc., are required to reveal the association of $\mathrm{HBoV}$-induced bronchiolitis with the development of atopy [32].

Although bocavirus is frequently associated with acute wheezing episodes, the studies on long-term consequences of $\mathrm{HBoV}$ infection are limited. The association of $\mathrm{HBoV}$ infection in early life and asthma is still unclear, and more data are required to establish this correlation. It was reported in young children that unlike $\mathrm{RV}, \mathrm{HBoV}$ infection was not associated with pro-inflammatory or Th2-type responses and the $\mathrm{RV}-\mathrm{HBoV}$ coinfection evoked non-Th2-type immune response [28]. In a study from Spain, in children hospitalized for $\mathrm{HBoV} / \mathrm{RSV}$ bronchiolitis, it was found that all children in the $\mathrm{HBoV}$ group developed recurrent wheezing, while half of the children in the HBoV group developed asthma and atopy [33]. In this prospective study, in children over 2 years of age hospitalized for acute, severe asthma exacerbation, $\mathrm{HBoV}$ was found to be the predominant demonstrating a significant correlation between $\mathrm{HBoV}$ infection and exacerbation of asthma. According to this study, HBoV can be a causative agent of asthma exacerbation due to the high frequency of $\mathrm{HBoV}$ infection in children suffering from asthma [34]. Another study reported that asthma and current wheezing were significantly associated with $\mathrm{HBoV}$-bronchiolitis in children than in RSV bronchiolitis in 5- to 7-year-old children. However, larger studies are needed to confirm these findings [35]. Altogether, broad-based studies based on demography, genetic predisposition, etc., are necessary to establish the correlation of $\mathrm{HBoV}$ infection in early life and asthma development.

\section{Immunogenicity Studies}

Currently, there is no vaccine available for $\mathrm{HBoV}$ infections for human use. Immunogenicity studies for development of vaccines against $\mathrm{HBoV}$ are still lacking. Since VP2 proteins are of high immunogenic value as of related B9 parvovirus, vaccination studies have focused on this protein as a potential vaccine candidate. In mice, strong humoral and cellular immune responses were induced in response to HBoV VP2-VLPs immunisation [36]. HBoV VLPs induced high titres of IgG antibodies which were further enhanced by immunization with $\mathrm{HBoV}$ VLPs with alum adjuvant. IFN- $\gamma$ production was 
induced in the splenocytes of mice immunized with HBoV1 and HBoV2 VLPs proved to be a potent activator of $\mathrm{T}$ cells as detected by elevated IFN- $\gamma$ production levels. These results demonstrate that HBoV VP2-VLPs administered in conjunction with alum adjuvant can enhance immunogenicity, clear exogenous virus, and protect against infection [36]. To lend support to these findings, the immunoreactivity of $\mathrm{HBoV}$ VP2 was found to be superior to VP1 in terms of immunoreactivity. Furthermore, most anti-HBoV antibodies in human serum reacted with viral capsid protein VP2 [37]. Altogether, these results further support the potential of VP2 as an effective vaccine candidate than VP1.

\section{Escape Mechanism}

It is well established that the immune system initiates a robust defence mechanism upon encounter with pathogens. Type I interferon (IFN) and the IFN-induced cellular antiviral immune responses are the primary defence mechanisms against viral infection. However, viruses have developed multiple strategies to counteract immune surveillance. The strategies employed by viruses include evasion from cytotoxic NK and T cells, blocking of antigen presentation, inhibition of IFN production, and antigenic mutations [38, 39]. Bocaviruses have evolved strategies to escape immune detection mostly by inhibition of IFN secretion. Whereas positive regulation of IFN signalling elicits rapid type I IFNs, negative regulation suppresses the excess production that can be detrimental to the host. A potential immune-evasion mechanism used by $\mathrm{HBoV}$ was discovered where $\mathrm{HBoV}$ inhibited both RNA- and DNA-induced IFN- $\beta$ production. The mechanism of inhibition was mediated by NP1 which suppressed IFN- $\beta$ production by targeting the IRF-3 signalling pathway. This pathway of inhibition of IFN helps $\mathrm{HBoV}$ to evade immune surveillance and replicate in the host [40]. On similar lines, in case of Porcine Bocavirus, the NS protein NP1 of PBoV inhibited Sendai virus-induced IFN- $\beta$ production and the subsequent expression of IFN-stimulating genes by interacting with the crucial DNA-binding sites of IRF-3 [41]. Another study delineated a pathway responsible for aberrant activation of IFN regulatory factor 3 pathway causing viral manipulation of the host innate immune system. The structural protein VP2 of HBoV1 modulates IFN pathway by targeting the ring finger protein 125 (RNF125), a negative regulator of type I IFN signalling, thereby enhancing SeVinduced IFN $-\beta$ production. This inhibition of negative regulator of type I IFN signalling causes manipulation of host immune networks, thereby facilitating virus replication [42].

Nuclear factor-kappa B (NF- $\kappa \mathrm{B})$ transcription factors play an important role in eliminating viruses through activation of multiple pathways. It has been demonstrated that HBoV NS1 and NS1-70 proteins blocked NF- $\mathrm{KB}$ activation in response to TNF- $\alpha$. These findings reveal a potential immune-evasion mechanism employed by Bocaviruses to dampen the effect of TNF- $\alpha$ and induce viralinduced pathogenesis. In addition to this, NS1 and NS170 proteins prove to be essential for viral DNA replication by interfering with TNF- $\alpha$ signalling transducers (TRAF2, IKK $\alpha, I K K \beta$, and IKK $\beta$ SS/EE). In short, NS1 and NS1-70 function as NF- $\kappa \mathrm{B}$ antagonists to help $\mathrm{HBoV}$ evade innate immunity [43]. Additionally, it was shown that the $\mathrm{N}$ terminus of $\mathrm{HBoV} \mathrm{NP} 1$ plays a critical role not only in its nuclear localization but also in its suppression of the type I IFN promoter [44]. Other than direct manipulation of the Type I IFN a pathway, HoBV also utilizes the host cell killing mechanism to survive the host immune response. HBoV1 infection-induces pyroptotic cell death rather than apoptotic or necroptotic cell death of human airway epithelia by disruption of barrier function, cell hypotrophy, and caspase- 1 and 11 activations. Consequently, it confers an advantage allowing $\mathrm{HBoV} 1$ to replicate in the airway epithelia [45]. The mechanism of immune evasion of $\mathrm{HBoV}$ is shown in Figure 3.

\section{Conclusion and Future Perspectives}

HBoV1 is a single-stranded DNA parvovirus that causes respiratory diseases, including lower respiratory tract infections and acute wheezing in infants, and gastrointestinal infections in adults. Immunopathogenicity of $\mathrm{HBoV}$ remains poorly characterized, mainly due to the lack of cell lines for in vitro studies and experimental animal models. Attempts to establish cell cultures with $\mathrm{HBoV}$ have been less successful due to limited permissiveness of cell lines for HBOV infection. Cell line HAEALI, previously used to infect a wide range of respiratory RNA viruses is presently being used to study $\mathrm{HBoV}$ infection.

Current knowledge about immune responses evoked in response to Bocavirus infection is insufficient. The precise mechanisms underlying $\mathrm{HBoV}$-specific T-cell immunity remains undefined. Existing data have revealed the role of T-helper cells in anti-HBoV immunity by promoting B-cell activity. It has been demonstrated that 
Fig. 3. Bocaviruses have evolved strategies to escape immune detection mostly by inhibition of IFN- $\beta$ production by targeting the IRF-3 and RNF125 signalling pathways NS1 and NS1-70 proteins function as NF$\kappa \mathrm{B}$ antagonists to help $\mathrm{HBoV}$ evade innate immunity. HBoV1 infection-induces pyroptotic cell death of host airway epithelia to facilitate viral replication. $\mathrm{HBoV}$, human bocavirus; NS, nonstructural.

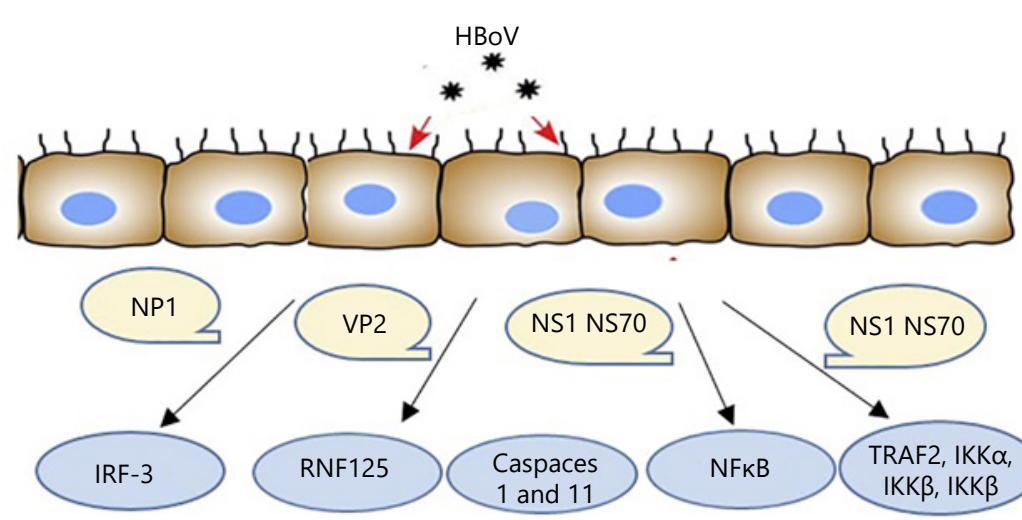

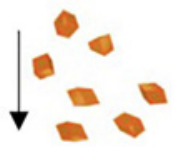

IFN- $\beta$

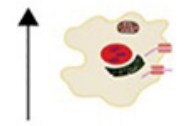

Pyroptic cell-death

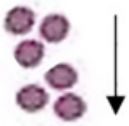

TNF- $\alpha$

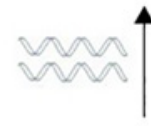

Viral DNA replication

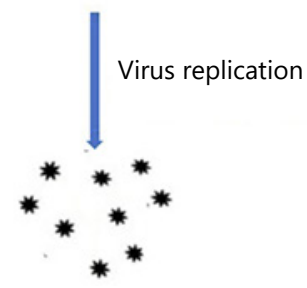

$\mathrm{HBoV}$ infection in infants and adults can induce the production of both Th1 and Th2 cytokines. Several studies have reported the induction of production of IFN- $\gamma$, IL-2, IL-13, and IL-10 in response to stimulation with $\mathrm{HBoV}$ VLPs, suggesting the role of CD4 T cells in $\mathrm{HBoV}$ infection. However, the role and the interplay of different immune cells viz. cytotoxic $\mathrm{T}$ and NK cells during $\mathrm{HBoV}$ infection are still unknown.

The persistence and reactivation of $\mathrm{HBoV}$ may be better explained by studying the mechanism through which $\mathrm{HBoV}$ evade the host's immune system. The escape strategies employed by $\mathrm{HBoV}$ mostly target IFN secretion pathways of the host cells. These involve NP1-mediated inhibition of IFN- $\beta$ production by targeting IRF- 3 signalling pathways and VP2-mediated negative regulation of type I IFN signalling. In addition to this, NS1 protein blocks NF- $\kappa \mathrm{B}$ activation which is an inherent factor for multiple immune signalling pathways. Altogether, the inhibitory roles played by NP1, NS 1, and VP2 proteins of $\mathrm{HBoV}$ result in manipulation of host immune networks, thereby promoting virus propagation.

Other than the above-mentioned pathways, HoBV also utilizes the host cell death to its advantage. HBoV1 induces pyroptotic rather than apoptotic or necroptotic host cell death by activation of anti-caspases. However, by inducing pyroptosis in host epithelial cells, $\mathrm{HBoV}$ initiates an inflammatory reaction leading to lung tissue injury in $\mathrm{HBoV}$-infected patients. Further investigations about the evasion mechanism employed by $\mathrm{HBoV}$ can expedite the development of effective therapy against $\mathrm{HBoV}$ infection.

$\mathrm{HBoV}$ also demonstrates the phenomenon known as original antigenic sin. It has been observed that infection with one $\mathrm{HBoV}$ type may, thus, inhibit the subsequent generation of antibodies towards the unique epitopes of another $\mathrm{HBoV}$ variant. This phenomenon has been corroborated by experimental evidence in rabbits and children infected with different $\mathrm{HBoV}$ types.

The development of an effective vaccine to combat viral infections should be of utmost priority. Previous research studies with other parvoviruses have confirmed that VLPs can be used as safe and effective vaccines. Similarly, in mice, HBoV VP2-VLPs have demonstrated good immunogenicity and induction of strong humoral and cellular immune responses, making them a promising candidate for $\mathrm{HBoV}$ vaccine. 
Vaccination is still the most effective method to prevent viral infections; however, highly mutating viruses and deficient response to vaccination present a challenge. Therefore, strategies based on nucleic acid-based molecules can serve as promising therapeutic interventions against respiratory viral infections to block viral gene expression. Nucleic acid-based therapeutic agents, such as short interfering RNAs (siRNA), ribozymes, deoxyribozymes (DNAzymes), aptamers, and antisense oligonucleotides, have shown potential in the management of respiratory virus infections under experimental conditions $[46,47]$. Although there are limitations in applying these strategies due to problems of instability in vivo and efficient delivery, antisense oligonucleotides have been studied extensively against several respiratory viruses with promising results. Many studies have reported effective in vivo antiviral activity using antisense compounds in experimental respiratory tract infections caused by RSV, influenza, etc. [48]. It can be of great interest to pursue an antisense strategy to combat bocavirus infection, parallel with the task of developing an effective vaccine against Bocavirus.

Since $\mathrm{HBoV}$ is ubiquitously prevalent in children and infants with respiratory tract infections, there is gathering evidence that $\mathrm{HBoV}$ is indeed a primary causative agent of respiratory diseases. The high prevalence of $\mathrm{HBoV}$ in dual infections and potentially serious and life-threatening clinical implications necessitate thorough investigations in future. A better perception of the natural course of $\mathrm{HBoV}$ infection, the pursuit to establish an experimental model and the development of a therapeutic regimen for preventing $\mathrm{HBoV}$ infection, including vaccines are urgently needed.

\section{Acknowledgements}

The authors thank the Deanship of Scientific Research and RSSU at King Saud University for their technical support.

\section{Conflict of Interest Statement}

The authors have no conflicts of interest to declare.

\section{Author Contributions}

Rauf Bhat wrote and drafted the review. Rauf Bhat and Fahad Almajhdi edited and approved the manuscript.

\section{References}

1 Allander T, Tammi MT, Eriksson M, Bjerkner A, Tiveljung-Lindell A, Andersson B. Cloning of a human parvovirus by molecular screening of respiratory tract samples. Proc Natl Acad Sci U S A. 2005;102(36):12891-6.

2 Kapoor A, Slikas E, Simmonds P, Chieochan$\sin \mathrm{T}$, Naeem A, Shaukat S, et al. A newly identified bocavirus species in human stool. J Infect Dis. 2009;199(2):196-200.

3 Jartti T, Hedman K, Jartti L, Ruuskanen O, Allander T, Söderlund-Venermo M. Human bocavirus-the first 5 years. Rev Med Virol. 2012;22(1):46-64.

4 Schildgen O, Qiu J, Söderlund-Venermo M. Genomic features of the human bocaviruses. Future Virol. 2012;7(1):31-9.

5 Gurda BL, Parent KN, Bladek H, Sinkovits RS, DiMattia MA, Rence C, et al. Human bocavirus capsid structure: insights into the structural repertoire of the parvoviridae. J Virol. 2010;84(12):5880-9.

6 Schildgen O. Human bocavirus: lessons learned to date. Pathogens. 2013;2(1):1-12.

7 Lüsebrink J, Schildgen V, Tillmann RL, Wittleben F, Böhmer A, Müller A, et al. Detection of head-to-tail DNA sequences of human bocavirus in clinical samples. PLoS One. 2011; 6(5):e19457.
8 Campe H, Hartberger C, Sing A. Role of human bocavirus infections in outbreaks of gastroenteritis. J Clin Virol. 2008;43(3):340-2.

9 Bastien N, Brandt K, Dust K, Ward D, Li Y. Human bocavirus infection, Canada. Emerg Infect Dis. 2006;12(5):848-50.

10 Deng X, Li Y, Qiu J. Human bocavirus 1 infects commercially available primary human airway epithelium cultures productively. J Virol Methods. 2014;195:112-9.

11 Sun B, Cai Y, Li Y, Li J, Liu K, Li Y, et al. The nonstructural protein NP1 of human bocavirus 1 induces cell cycle arrest and apoptosis in Hela cells. Virology. 2013;440(1):75-83.

12 Zou W, Cheng F, Shen W, Engelhardt JF, Yan Z, Qiu J. Nonstructural protein NP1 of human bocavirus 1 plays a critical role in the expression of viral capsid proteins. J Virol. 2016; 90(9):4658-69.

13 Foulongne V, Rodière M, Segondy M. Human bocavirus in children. Emerg Infect Dis. 2006; 12(5):862-3.

14 Guidotti LG, Chisari FV. Noncytolytic control of viral infections by the innate and adaptive immune response. Annu Rev Immunol. 2001;19:65-91.

15 Braciale TJ, Sun J, Kim TS. Regulating the adaptive immune response to respiratory virus infection. Nat Rev Immunol. 2012;12(4): 295-305.
16 Guido M, Tumolo MR, Verri T, Romano A, Serio F, De Giorgi M, et al. Human bocavirus: current knowledge and future challenges. World J Gastroenterol. 2016;22(39):8684-97.

17 Lindner J, Zehentmeier S, Franssila R, Barabas S, Schroeder J, Deml L, et al. CD4+ Thelper cell responses against human bocavirus viral protein 2 viruslike particles in healthy adults. J Infect Dis. 2008;198(11):1677-84.

18 Endo R, Ishiguro N, Kikuta H, Teramoto S, Shirkoohi R, Ma X, et al. Seroepidemiology of human bocavirus in Hokkaido prefecture, Japan. J Clin Microbiol. 2007;45:3218-23.

19 Kumar A, Filippone C, Lahtinen A, Hedman L, Söderlund-Venermo M, Hedman K, et al. Comparison of Th-cell immunity against human bocavirus and parvovirus B19: proliferation and cytokine responses are similar in magnitude but more closely interrelated with human bocavirus. Scand J Immunol. 2011; 73(2):135-40.

20 Allander T, Jartti T, Gupta S, Niesters HG, Lehtinen P, Osterback R, et al. Human bocavirus and acute wheezing in children. Clin Infect Dis. 2007;44(7):904-10.

21 Legg JP, Hussain IR, Warner JA, Johnston SL, Warner JO. Type 1 and type 2 cytokine imbalance in acute respiratory syncytial virus bronchiolitis. Am J Respir Crit Care Med. 2003; 168(6):633-9. 
22 Chung JY, Han TH, Kim JS, Kim SW, Park CG, Hwang ES. Th1 and Th2 cytokine levels in nasopharyngeal aspirates from children with human bocavirus bronchiolitis. J Clin Virol. 2008;43(2):223-5.

23 Kantola K, Hedman L, Tanner L, Simell V, Mäkinen M, Partanen J, et al. B-cell responses to human bocaviruses 1-4: new insights from a childhood follow-up study. PLoS One. 2015; 10(9):e0139096.

24 Meriluoto M, Hedman L, Tanner L, Simell V, Mäkinen M, Simell S, et al. Association of human bocavirus 1 infection with respiratory disease in childhood follow-up study, Finland. Emerg Infect Dis. 2012;18(2):264-71.

25 Hedman L, Söderlund-Venermo M, Jartti T, Ruuskanen O, Hedman K. Dating of human bocavirus infection with protein-denaturing IgG-avidity assays-Secondary immune activations are ubiquitous in immunocompetent adults. J Clin Virol. 2010;48(1):44-8.

26 Neske F, Prifert C, Scheiner B, Ewald M, Schubert J, Opitz A, et al. High prevalence of antibodies against polyomavirus WU, polyomavirus KI, and human bocavirus in German blood donors. BMC Infect Dis. 2010;10: 215.

27 Song JR, Jin Y, Xie ZP, Gao HC, Xiao NG, Chen WX, et al. Novel human bocavirus in children with acute respiratory tract infection. Emerg Infect Dis. 2010;16(2):324-7.

28 Lukkarinen H, Söderlund-Venermo M, Vuorinen T, Allander T, Hedman K, Simell O, et al. Human bocavirus 1 may suppress rhinovirus-associated immune response in wheezing children. J Allergy Clin Immunol. 2014; 133(1):256-4.

29 Sobkowiak P, Mikoś M, Bręborowicz A, Szczepankiewicz A. Human bocavirus and metapneumovirus in acute wheezing in children-Is there a link with atopy? Clin Respir J. 2020; 14(12):1201-7.
30 Midulla F, Scagnolari C, Bonci E, Pierangeli A, Antonelli G, De Angelis D, et al. Respiratory syncytial virus, human bocavirus and rhinovirus bronchiolitis in infants. Arch Dis Child. 2010;95(1):35-41.

31 Del Rosal T, García-García ML, Calvo C, Gozalo F, Pozo F, Casas I. Recurrent wheezing and asthma after bocavirus bronchiolitis. Allergol Immunopathol. 2016;44(5):410-4.

32 Turunen R, Koistinen A, Vuorinen T, Arku B, Söderlund-Venermo M, Ruuskanen O, et al. The first wheezing episode: respiratory virus etiology, atopic characteristics, and illness severity. Pediatr Allergy Immunol. 2014;25(8): 796-803.

33 Coverstone AM, Wang L, Sumino K. Beyond respiratory syncytial virus and rhinovirus in the pathogenesis and exacerbation of asthma: the role of metapneumovirus, bocavirus and influenza virus. Immunol Allergy Clin North Am. 2019;39(3):391-401.

34 Vallet C, Pons-Catalano C, Mandelcwajg A, Wang A, Raymond J, Lebon P, et al. Human bocavirus: a cause of severe asthma exacerbation in children. J Pediatr. 2009;155(2):286-8.

35 Del Rosal T, García-García ML, Calvo C, Gozalo F, Pozo F, Casas I. Recurrent wheezing and asthma after bocavirus bronchiolitis. $\mathrm{Al}$ lergol Immunopathol. 2016;44(5):410-4.

36 Deng ZH, Hao YX, Yao LH, Xie ZP, Gao HC, Xie LY, et al. Immunogenicity of recombinant human bocavirus-1,2 VP2 gene virus-like particles in mice. Immunology. 2014;142(1): 58-66.

37 Kantola K, Hedman L, Allander T, Jartti T, Lehtinen P, Ruuskanen O, et al. Serodiagnosis of human bocavirus infection. Clin Infect Dis. 2008;46(4):540-6.

38 Lucas M, Karrer U, Lucas A, Klenerman P. Viral escape mechanisms: escapology taught by viruses. Int J Exp Pathol. 2001;82(5):26986.
39 Alcami A, Koszinowski UH. Viral mechanisms of immune evasion. Mol Med Today. 2000;6(9):365-72.

40 Zhang Z, Zheng Z, Luo H, Meng J, Li H, Li Q, et al. Human bocavirus NP1 inhibits IFN- $\beta$ production by blocking association of IFN regulatory factor 3 with IFNB promoter. J Immunol. 2012;189(3):1144-53.

41 Zhang R, Fang L, Wu W, Zhao F, Song T, Xie $\mathrm{L}$, et al. Porcine bocavirus NP1 protein suppresses type I IFN production by interfering with IRF3 DNA-binding activity. Virus Genes. 2016;52(6):797-805.

42 Luo H, Zhang Z, Zheng Z, Ke X, Zhang X, Li $Q$, et al. Human bocavirus VP2 upregulates IFN- $\beta$ pathway by inhibiting ring finger protein 125 -mediated ubiquitination of retinoic acid-inducible gene-I. J Immunol. 2013; 191(2):660-9.

43 Liu Q, Zhang Z, Zheng Z, Zheng C, Liu Y, Hu Q, et al. Human bocavirus NS1 and NS1-70 proteins inhibit TNF- $\alpha$-mediated activation of NF-кB by targeting p65. Sci Rep. 2016;6:28481.

44 Zhang R, Fang L, Cai K, Zeng S, Wu W, An K, et al. Differential contributions of porcine bocavirus NP1 protein N- and C-terminal regions to its nuclear localization and immune regulation. J Gen Virol. 2016;97(5):1178-88.

45 Deng X, Zou W, Xiong M, Wang Z, Engelhardt JF, Ye SQ, et al. Human parvovirus infection of human airway epithelia induces pyroptotic cell death via inhibiting apoptosis. J Virol. 2017;91(24):e01533-17.

46 Abe T, Mizuta T, Hatta T, Miyano-Kurosaki $\mathrm{N}$, Fujiwara M, Takai K, et al. Antisense therapy of influenza. Eur J Pharm Sci. 2001;13(1): 61-9.

47 Potaczek DP, Garn H, Unger SD, Renz H. Antisense molecules: a new class of drugs. J Allergy Clin Immunol. 2016;137(5):1334-46.

48 Torrence PF. 2-5A-antisense chimeras: inhibitors of respiratory syncytial virus infection. Curr Opin Mol Ther. 1999;1(3):307-15. 